\title{
JUAN RULFO, LECTOR DE KNUT HAMSUN
}

\author{
POR \\ SILVIA LORENTE-MURPHY \\ Purdue University North Central
}

Rulfo fue desde muy joven un ávido lector, sobre todo, de narradores del realismo ruso y nórdico, cuyas obras llegaban a Hispanoamérica en excelentes traducciones españolas generalmente vertidas del francés: Andreiev, Korolenko, Tolstoy, Dostoievsky, Gorky, Chejov, Hamsun, Björnson, Sillampa, Laxness, Ramuz y Giono ${ }^{1}$. «Tuve alguna vez la teoría --dice Rulfo- de que la literatura nacía en Escandinavia, en la parte norte de Europa, y luego bajaba al centro, de donde se desplazaba hacia otros sitios ${ }^{2}$.

El movimiento positivista que modernizaba al resto del mundo y que ponía al descubierto los problemas sociales de la época no había logrado enraizar en España. La literatura peninsular, en su técnica y en sus propósitos, aparecía como una forma tardía de la novela europea de la primera mitad del siglo XIX y, más concretamente, un reflejo a menudo desvirtuado del realismo francés. La novela española finisecular, al menos en sus primeros intentos, se identifica con el costumbrismo o vuelve a la tradición cervantina o al género picaresco, concediendo mayor importancia a la pintura de tipos y costumbres que al análisis psicológico o social.

Este adormecimiento de las letras españolas ahuyentó, naturalmente, a lectores americanos ansiosos de identificarse con los grandes movimientos sociales europeos, de conocerse a sí mismos y de poner de manifiesto

1 La crítica ha señalado, además, la influencia de Kafka, Proust y Joyce y, muy especialmente, la de Faulkner en la obra de Rulfo.

2 Citado por Luis Harss, "Juan Rulfo o la pena sin nombre», en Recopilación de textos sobre Juan Rulfo (La Habana: Centro de Investigaciones Literarias. Casa de las Américas, 1969), p. 37. 
sus propios problemas políticos, sociales y económicos, e integrarse a la realidad del siglo xx. Los lectores americanos, entonces, se vuelcan hacia las letras rusas y escandinavas principalmente, en donde los problemas sociales y políticos no se escamoteaban. Era también visible que, en esta literatura, un nuevo modo de presentar la realidad se estaba llevando a cabo. En efecto, muchos aspectos de la innovación de la novela europea moderna tienen su antecedente en los autores citados y, sobre todo, en la fascinante obra del noruego Knut Hamsun (1859-1952), quien contó con muchos lectores americanos. Juan Rulfo declara haberlo leído y gustado.

En nuestra opinión, Rulfo ha asimilado de Hamsun rasgos que no sólo son notables en su obra, sino que la caracterizan.

\section{EL MAGISTERIO DE HAMSUN}

Hamsun presenta en la literatura un punto de vista diferente en el planteamiento de los problemas humanos. Su perspectiva se aleja tanto del descriptivismo científico y del determinismo naturalista como de la rebeldía planfletaria, la idealización del ser humano y la elaborada oratoria del romanticismo. La subjetividad (que jamás cae en el sentimentalismo quejumbroso), el fragmentarismo, el uso de flashbacks, la presentación del antihéroe y del lenguaje popular, así como la importancia concedida a los aspectos irracionales de la conciencia son, en efecto, notas relevantes de la literatura contemporánea que se hallan ya presentes en la obra de Hamsun, aun en sus escritos más tempranos.

Para Hamsun, la realidad es siempre interior, tanto cuando se trata del análisis de un individuo aislado como del de una sociedad entera. Hamsun rechaza el realismo externo, la pretensión de reproducir la realidad fuera de nosotros, la descripción de acontecimientos como acumulaciones y la noción de «carácter» cuya constancia y solidez niega. Exige, en cambio, la fidelidad a lo sentido, a lo vivido, y no en una sola pieza, sino más bien en fragmentos generalmente oscuros y confusos, pero vivos.

«Hamsun's intention was not to show Entwicklung but rather a soul's dialogue with its alter superior ego. Indeed, he was so much interested in his protagonist's inner monologues that the novel suffers from lack of development. The author claimed he had aimed at that effect by playing, as he put it, his whole plot on one single string», comenta Harald Naess refiriéndose a la novela Hambre ${ }^{3}$. Tal como

\footnotetext{
3 Harald Naess, Knut Hamsun (Boston: Twayne Publishers, 1984), pp. 32-33.
} 
Kierkegaard y el holandés Jacobsen, Hamsun llevó a cabo un movimiento introspectivo primero para, después, desde una perspectiva subjetiva, interpretar y valorar el mundo que lo rodeaba.

El estilo de Hamsun, algo nuevo en la literatura europea de la época, abunda en interjecciones, frases cortas (a veces de una sola palabra), en preguntas, respuestas y repeticiones. Pero esta prosa aparentemente sin desarrollo, vacilante a veces, formada como por toques de staccato, rejuveneció a la literatura del Norte con la naturalidad del habla diaria en sus frecuentes repeticiones, sus irracionalidades y su carencia de tono discursivo:

- ¿Por qué no dice usted nada?

- iAh, qué gentil es usted! - dije-. Estoy prendado de usted, profundamente apasionado. No puedo con ello. Es usted el ser más admirable que... Sus ojos tienen a veces el resplandor; no he visto nunca nada parecido; se diría que son flores, ¿eh? No, no, quizá no sean flores, pero... Estoy iocamente enamorado de usted y no puedo hacer nada. ¿Cómo se llama? En serio, tiene usted que decirme cómo se 11 ama... ${ }^{4}$

I'll explain everything afterwards. But how far do you trust me? I mean how much faith do you hace in me? I'm not making any sense, but it's so hard to begin. Would you believe me if, for instance, I told you I was very fond of you? You must be aware of that. But if I should go a step further - I mean, if I should ask you to be my wife. My wife- there I've said it! Not just my mistress but my wife. Good God, what's the matter? No, please let me hold your hand. I'll be able to explain myself so much better, and I'm sure you'tl understand ${ }^{5}$.

Se trata, ante todo, de un estilo "presentativo», pues no intenta recrearse en sí mismo o transmitir mensajes directamente, o imponer el criterio del narrador al criterio del lector ficticio. Las obras de Hamsun muestran, en efecto, una rebelión contra el didactismo naturalista y el tono moralizador de los escritos de Björnson, por ejemplo.

Por otra parte, el tono antidramático de la voz narradora al comunicar situaciones patéticas, a menudo de padecimiento intolerable, sin alterarse, es también algo nuevo que Hamsun aporta a la literatura de la época. En el capítulo final de Un vagabundo con sordina (1909), por ejemplo, el personaje principal regresa a la rudimentaria choza donde

4 Knut Hamsun, Hambre. Traducción de José Viana (Barcelona: Plaza y Janés, S. A., 1979), p. 91. Todas las citas corresponden a esta edición.

5 Knut Hamsun, Mysteries. Translated from the Norwegian by Gerry Bothmer (New York: Farrar, Strans and Giroux, 1971), p. 253. 
malamente se cobija durante las noches, caminando despacio, con frio, hambriento, sin ningún recurso, pero mostrando una especie de resignación o indiferencia como si nada importa o como si el autor mismo sintiera desgano de contar situaciones dolorosas, pero debe hacerlo porque lamentablemente son reales.

It is starting to freeze as I wander back home to my logger's cabin; soon the frost bites into moors and marshes, and makes the going easy. I saunter onward, slowly and indifferently, with my hands in my pockets. Why should I hurry? It makes no difference where I $\operatorname{am}^{6}$.

Hambre, su primera novela de fama, publicada en 1890, podría ser leída como un ejemplo del naturalismo escandinavo posterior a 1880, ya que muchas escenas están marcadas por un realismo desnudo, difícil de sobrepasar. Pero el libro, a la vez, marca el final del período naturalista en el Norte, por sus ingredientes de análisis del subconsciente, la voluntad del protagonista de vencer las circunstancias, sus fantasías, su cuota de humor y la ausencia de una intención didáctica. Esto, claro está, no significa que la obra carezca de una valoración de las condiciones políticas y sociales de la época en Noruega, ya que el libro es, en rigor, el grito doloroso del hombre frente a una organización social absurda que lo somete a las más humillantes situaciones de desempleado.

Hambre es sencillamente la novela de un periodista desempleado que pasa días y días sin comer. En ella no hay, en realidad, ninguna intriga, sólo la exposición simple de una situación determinada; situación, en este caso, deplorable, que refleja una sociedad en un momento interesante de su desarrollo. Tampoco encontramos rastros de «color local», ya que de Kristiania sólo obtenemos vistas ocasionales desde una ventana, uno que otro objeto que llama la atención del protagonista en sus largas caminatas y la bella vista del mar, desde el puerto. Los personajes nunca aparecen delineados acabadamente, sino que se los introduce en la novela por medio de sus palabras o una muy somera descripción por parte del narrador.

A pesar de la angustia corroyente del tema, Hambre no tiene nada que la relacione con el naturalismo imperante entonces. Hamsun sustituye el estilo científico de la época por un lenguaje adecuado para expresar lo inconsciente e incognoscible:

6 Knut Hamsun, The Wanderer. Under the Autumn Star and On Muted Strings. Translated from the Norwegian by Oliver and Guunvor Stallybrass (New York: Farrar, Straus and Giroux, 1975), pp. 280-281. 
Y mi imaginación desbocada escapa de nuevo por los caminos de la aventura. Me doy cuenta de la incoherencia de mis palabras, y no pronuncio ni una sin oírla y entenderla. Me digo a mí mismo « ¡Ya vuelves a divagar!» Y, sin embargo, no puedo impedirlo. Era como estar acostado sin dormir y hablar en sueños. Mi cabeza está ligera, sin dolor, completamente despejada, y en mi alma no hay nubes. Voy a la deriva, sin oponer ninguna resistencia (Hambre, p. 91).

La mayor parte del libro, en efecto, trata del subconsciente del protagonista, de sus acciones guiadas más por el instinto que por la razón, pero también (nuevamente en contra del naturalismo imperante) de la tenacidad con que lleva a cabo sus esfuerzos literarios a pesar de la futilidad de los mismos, es decir, de su esperanza nunca completamente extinguida.

El tema del hambre y el desamparo tampoco revela en esta novela: un cuestionamiento social. Hamsun no es un activista y la protesta sólo aparece de manera implícita en el texto mediante la presentación de la. miseria injusta del protagonista, casi siempre resignado a sus circunstancias, excepto en los momentos límites, cuando dirige su imprecación. a Dios.

Si un periodista no puede matar el hambre, esto significa que no le están pagando su trabajo como merece, al menos para no morir de inanición. Hamsun, sin embargo, no explicita una protesta, aunque el lector, de todos modos, la capta, pues está ahí, representada en esos. personajes de Hambre y de sus otras obras, quienes hablan por sí mismos de su miseria en los momentos en que adquiría forma la burguesía industrial moderna:

Me asomé a la ventana que daba a la calle de los Carreteros, donde algunos niños, pobremente vestidos, jugaban arrojảndose unos a otros una botella vacía y gritando a voz en cuello. Un carro de mudanzas pasó cerca de ellos, rodando lentamente; sería una familia desahuciada, que cambiaba de domicilio fuera de la época de mudanzas. Tal fue la idea que tuve al momento. El carro iba cargado de camas y somiers, camas apolilladas, sillas y cómodas, pintadas de rojo, con tres pies, esteras, hierros viejos, batería de cocina. Una muchacha, casi una niña, muy fea y con la nariz destilante de constipado, iba tendida. en todo lo alto de la carga y se agarraba con sus pobres manos amoratadas para no caerse. Se acomodaba sobre un montón de horribles colchones húmedos, en que habían dormido niños, y miraba a los muchachos que se lanzaban la botella vacía... (Hambre, pp. 196-197).

A partir de la publicación de Hambre, Hamsun sigue creando personajes semejantes al ser famélico de su primer libro. Se trata, por lo 
general, de una especie de vagabundo, complejo, enigmático, enamorado de la naturaleza, sin hogar y sin trabajo seguro, en el seno de una sociedad que le resulta extraña. Este ser errante y errático puede ser alternativamente despectivo, tierno, arrogante, violento y aun cruel, pero casi sin excepciones llena su soledad con fantasías en las que resulta dif́́cil distinguir lo verídico de lo imaginado, con ensueños eróticos y un culto casi panteísta a la naturaleza. Todas estas características se encuentran en Johan Nagel de Misterios (1892), en Thomas Glann de Pan (1894) y, más tarde, en el protagonista de Augusto (1930). Todos ellos inadaptados, nómadas, desbordantes de alucinaciones y poesía, pero todos ellos hombres comunes, pobres, resignados a su suerte los más y sin siquiera esbozar una protesta social.

En Bendición de la tierra, de 1917, Hamsun aporta algo nuevo con el personaje Isak, esa especie de divinidad telúrica sobre la tierra de la cual ha surgido, que representa el triunfo del hombre sobre la adversidad; el hombre de voluntad férrea y fecunda que vencerá las dificultades y creará su futuro y el de sus descendientes a fuerza de trabajo y fe en el porvenir.

Isak Walked bareheaded, in Jesu name, a sower. Like a tree-stump with hands to look at, but in his heart like a child ${ }^{7}$.

Bendición de la tierra es realmente una obra optimista, caracterizada por la fe en la capacidad humana y en la facultad creativa del hombre. La obra de Hamsun, desde Hambre hasta Bendición de la tierra, significa la ruptura del naturalismo en Europa y el comienzo de una nueva concepción de la literatura narrativa.

\section{RULFo EN LA NUEVA MODALIDAD NARRATIVA}

En Hispanoamérica, la quiebra del realismo decimonónico se produce con cierto retraso; sus efectos plenos recién empiezan a observarse después de 1930. Para el movimiento literario que dominó la prosa hispanoamericana entre 1920 y 1945, la literatura es un medio para presentar las condiciones políticas, económicas y sociales de países que venían experimentando los efectos económicos de dos posguerras. El impulso principal de las obras llamadas criollistas proviene de la necesidad de los autores de conocerse a sí mismos a través de su tierra y de desper-

7 Knut Hamsun, Growth of the Soil. Translated from the Norwegian by W. W. Worster (New York: Alfred A. Knopf, 1968), pp. 30-31. 
tar una conciencia nacional en los lectores. Así, se revaloran los elementos autóctonos, se intensifica la crítica social, se escribe sobre temas estrictamente americanos, predominando el estilo descriptivo y con fuerte sabor vernáculo.

Para la época en que aparece El llano en llamas (1953), la serie de cuentos de Juan Rulfo, el realismo criollista, sin embargo, ya resultaba hueco y elusivo en interpretaciones y las circunstancias reclamaban una posición crítica de radio geográfico más amplio y de valores más universales. Manuel Rojas, con anterioridad, ya se había acercado a la nueva modalidad, que tendrá su culminación en Rulfo. «El vaso de leche», cuento de 1929, parece, en efecto, extraído de las páginas de Hlambre por su ambiente, tema y lenguaje; la primacía del ser humano y su visión antifatalista de la vida. En el cuento, Rojas, tal como Hamsun en su novela, no se preocupa tanto por la protesta social explícita como por el análisis del estado emocional de una persona que está pasando hambre y toda clase de privaciones ${ }^{8}$. Rojas, sin embargo, no produjo el impacto de Rulfo, aun cuando su novela Hijo de ladrón (1951), antecede a El llano en llamas en dos años y teniendo en cuenta que la popularidad de Rulfo, realmente, no comienza hasta la aparición de su novela Pedro Páramo, en 1955.

Se puede decir con justicia que Rulfo terminó con el cuento criollo y abrió paso a una interpretación que prescinde de elementos externos para dirigirse a lo más esencial y presentar la realidad no ya como enunciación testimonial, sino como interpretación crítica, valorativa y de alcances universales.

El estilo de Juan Rulfo, en apariencia descuidado, lento, vacilante; estilo que representa los movimientos de la conciencia; sobrio, sugestivo y cadencioso, recuerda también páginas de Hamsun, donde la concentración temática, la operación de síntesis y el alto poder evocativo revelan un modo muy diferente de representar el mundo.

Leemos en Rulfo:

-Ya mirará usted ese viento que sopla sobre Luvina. Es pardo. Dicen que porque arrastra arena del volcán; pero lo cierto es que es un aire negro. Ya lo verá usted. Se planta en Luvina prendiéndose de las cosas como si las mordiera?

8 Véase Manuel Rojas, «El vaso de leche», en $E l$ delincuente (Santiago de Chile: Empresa Editora Zig-Zag, S. A. 1968), pp. 37-54.

9 Juan Rulfo, «Luvina» en Pedro Páramo y El llano en llamas (Barcelona: Editorial Planeta, 1975), pp. 203-204. Todas las citas corresponden a esta edición, excepto la que se hace de «Paso del Norte», que se consigna aparte. 
Y no podemos dejar de comparar esta prosa con la de Hamsun:

Estoy acostado en mi buhardilla, no duermo; oigo sonar las seis en un reloj vecino. Hay mucha claridad y la gente comienza a moverse por la escalera. La pared de mi habitación, correspondiente a la puerta, está empapelada con números viejos del «Morgenbladet». (Hambre, p. 5.)

En la prosa de Rulfo, tal como en la de Hamsun, especialmente en Hambre, encontramos un empeño deliberado por condensar la materia narrativa, apuntando continuamente a lo esencial y apelando casi siempre al sobrentendido. Las frases son, por lo general, cortas y el lenguaje, lacónico y repetitivo, sin aparente desarrollo secuencial, con trazos de morosidad e intensificación del tiempo detenido:

-Son las cuatro de la tarde.

Ese alguien es Melitón. Junto con él, vamos Faustino, Esteban y yo. Somos cuatro. Yo los cuento: dos adelante, otros dos atrás. Miro más atrás y no veo a nadie. Entonces me digo: «Somos cuatro.» Hace rato, como a eso de las once, éramos veintitantos; pero puñito a puñito se han ido desperdigando hasta quedar nada más este nudo que somos nosotros («Nos han dado la tierra», p. 129).

Notamos, además, la estrategia hamsuniana de «dosificación» en Rulfo, en esa forma de ir entregando información después que los hechos ya han transcurrido y el narrador parecía haberlos olvidado. La trama completa de Un vagabundo con sordina se apoya en el presupuesto de que el personaje ha estado enamorado de la esposa de su patrón, dato que se da en un libro anterior, Bajo la estrella de otoño, y la aventura amorosa de ella con otro hombre y su presunto suicidio también nos sorprenden, porque nos enteramos de los dos episodios cuando ya han ocurrido: y la información nos es dada progresivamente y en «retazos». Así, en el párrafo de Rulfo citado anteriormente existe una sinfonía en cuanto mayor, pero luego se cambia de número «a eso de las once», que hacen un total de «veintitantos». Sólo ahora nos enteramos de que el llano debían repartírselo una treintena de campesinos, es decir, una masa de revolucionarios cesantes representada por los únicos cuatro que pueden dar testimonio del engaño post-revolucionario.

También en «No oyes ladrar los perros» la información aparece en forma gradual y oportuna. Lo primero que sabemos es que un hombre camina dificultosamente durante la noche; luego, que ese hombre es viejo y que carga a sus espaldas al hijo herido. Los dos hombres cambian muy pocas palabras. Compadecemos al herido hasta que comienza la 
reprimenda del padre («-Todo esto que hago, no lo hago por usted. Lo hago por su difunta madre» [ «No oyes ladrar los perros», p. 223]), y entonces nos damos cuenta de que las relaciones entre padre e hijo no son buenas. Pero es sólo al final del cuento cuando descubrimos que Ignacio, el hijo, lamentablemente incapacitado sobre las espaldas de su padre, es nada menos que un facineroso al que hemos estado compadeciendo piadosamente. Su padre es el que nos lo hace saber:

He maldecido la sangre que usted tiene de mí. La parte que a mí me tocaba la he maldecido. He dicho: « iQue se le pudra en los riñones la sangre que yo le di!» Lo dije desde que supe que usted andaba trajinando por los caminos, viviendo del robo y matando gente... Y gente buena («No oyes ladrar los perros», p. 223).

Este recurso de «dosificación» de datos que está sugerido en la obra de Hamsun, Rulfo lo ha elaborado plenamente obteniendo óptimos resultados.

Característica de la prosa rulfiana es también esa especie de apatía de que hablábamos al referirnos a Hamsun, en que el narrador hace partícipe al lector de los hechos más lamentables sin inmutarse, sin dar muestras de reacción emocional alguna:

Pero al quitarse él de enfrente, la luz de la luna hizo brillar la aguja de arria que yo había clavado en el costal. Y no sé por qué, pero de pronto comencé a tener una fe muy grande en aquella aguja. Por eso, al pasar Remigio Torrico por mi lado, desensarté la aguja y sin esperar otra cosa se la hundí a él cerquita del ombligo. Se la hundí hasta donde le cupo. Y allí le dejé («La cuesta de las Comadres», pp. 141-142).

En «E1 hombre», un testigo ocular relata su encuentro con un cadáver sin el menor asomo de piedad o aprensión:

Primero creía que se había doblado al empinarse sobre el río y no había podido ya enderezar la cabeza y que luego se había puesto a resollar agua, hasta que le vi la sangre coagulada que le salía por la boca y la nuca repleta de agujeros como si lo hubieran taladrado («El hombre», p. 159).

$\mathrm{Y}$ en «Talpa», un hombre relata fríamente la forma en que contribuyó a la muerte de su hermano:

Porque la cosa es que a Tanilo Santos entre Natalia y yo lo matamos. Lo llevamos a Talpa para que se muriera. Y se murió. Sabíamos 
que no aguantaría tanto camino; pero, así y todo, lo llevamos empujándolo entre los dos, pensando acabar con él para siempre. Eso hicimos («Talpa», pp. 167-168).

Ahora bien, Rulfo, como Hamsun, no es un intelectual, ni un teórico, ni un agitador político. Cuando Rulfo escribe, no lo hace con el propósito consciente de formular una protesta social ni de crear un pathos acrático. Simplemente escribe sobre lo que ve, y al hacerlo, toda denuncia formulada se vuelve innecesaria.

El mundo que se nos describe en El llano en llamas, por medio de un estilo parco y severo, es el mundo fallido de los ideales liberadores de la Revolución Mexicana, aunque Rulfo, tal como lo había hecho Hamsun, se abstenga de llevar a cabo un análisis dialéctico de las circunstancias. En la serie de cuentos, en efecto, se muestra mucho más de lo que se dice; las palabras corresponden al lenguaje sencillo y práctico del hombre de campo, quien, por otra parte, no necesita ser locuaz, ya que su sola presencia nos revela el mundo de postergación, de injusticia y abandono en que vive:

... nos estamos muriendo de hambre. La muerte y los nietos y este su hijo, como quien dice toda la descendencia, estamos ya por parar las patas y caernos bien muertos. $Y$ el coraje que da es que es de hambre ${ }^{10}$.

En la mayoría de los cuentos de Rulfo, y muy especialmente en la novela Pedro Páramo, encontramos la realidad mexicana trascendida, desbordando sus límites de espacio y tiempo. Profundizando en sus orígenes, Rulfo llega no sólo a la esencia del mexicano, sino del hombre en general; a los problemas antagónicos de la vida y la muerte, de la opresión y la libertad, del sufrimiento y la felicidad, del desencanto y la esperanza, por medio de un realismo que logra captar, al igual que la obra de Hamsun, la multiplicidad de matices con que se presenta la vida; un realismo amplio, alejado de la unilateralidad del naturalismo del siglo xIX en general, sin impedimentos para acercarse a lo misterioso, lo desconocido, lo irracional. Así lo atestigua la perspectiva entera desde la que se escribe Pedro Páramo, la muerte, y así lo atestiguan los procesos subconscientes e irracionales de los protagonistas, tanto en Pedro Páramo como en El llano en llamas.

En cuanto a los personajes, no encontramos en Rulfo la descripción detallada de ninguno de ellos; aparecen en sus obras esbozados me-

10 Juan Rulfo «Paso del Norte», en El llano en llamas (México: Fondo de Cultura Económica, 1961), p. 120. 
diante trazos rápidos y certeros, pero llegamos a conocerlos por lo que dicen o piensan o lo que otros personajes opinan de ellos. De la misma forma que logramos conocer a los personajes de Hamsun siguiendo la trayectoria de sus pensamientos y alucinaciones, así conocemos a los hombres de Rulfo, aparentemente pasivos unos, tenaces otros, violentos y crueles otros.

De la narrativa del autor mexicano podemos decir lo que en general hemos hecho notar acerca de la obra de Knut Hamsun: lo importante no es el desarrollo o la trama o los personajes vistos desde fuera, sino el agudo análisis interior de personas generalmente privadas de lo esencial y sin posibilidades (al menos inmediatas) de mejorar su situación.

En Rulfo, la carencia de medios económicos, la falta de oportunidades, la falta de libertad, son los factores que hacen que sus personajes, aunque tenaces y con potencialidad para triunfar en la vida los más, aparezcan oprimidos, escépticos y aparentemente sin ninguna posibilidad de cambiar su destino.

Rulfo, en efecto, no llega a concebir esa especie de superhombre nietzschiano que Hamsun logra con Isak de Bendición de la tierra. Sus hombres todavía no tienen la tierra ni las herramientas para cultivarla, como tampoco la libertad para construir su propio futuro. Sin embargo, nos negamos a catalogar al autor de fatalista o escéptico. Si bien es cierto que sus narraciones no rezuman optimismo, sí denotan una actitud de examen, de denuncia (denuncia no explícita, pero no por ello menos efectiva), una búsqueda de la bondad y un deseo ardiente de reivindicar al pueblo mexicano.

El hombre de Rulfo parece esperar, esperar mucho, a veces una eternidad, como ocurre en Pedro Páramo. Pero espera algo concreto. El dio, una vez, pruebas de una vigorosa voluntad para llevar a cabo una empresa social de verdadero progreso: la Revolución, que, aunque inacabada, sirvió para mostrar el potencial humano de México, potencial que suele hacerse explícito en algunas páginas de Rulfo.

Desde el momento en que se adopta una posición crítica sobre la realidad que se examina, tal como lo hace Hamsun especialmente en su libro Hambre, existe, en nuestro parecer, una genuina convicción de que esa realidad puede cambiar. Esta misma actitud positiva encontramos en Rulfo en su exposición parca y casi silenciosa de la injusticia y una fe en la esperanza tímida, pero esperanza al fin, de que algún día la opresión y el agobio se desmoronarán «como un montón de piedras», así como el cacique Pedro Páramo, y el mexicano recuperará su tierra, su libertad, su dignidad. 
La actitud crítica pero esperanzada, la carencia de discurso «panfletista», la parquedad de las descripciones, el predominio de lo «mostrado» sobre lo «contado», la minimización del aspecto externo frente a lo subjetivo, el estilo fragmentario y con toques de staccato, son notas que individualizan la obra de Rulfo tal como individualizaron la de Knut Hamsun.

El entorno social de los dos autores difiere, naturalmente, como difieren las circunstancias geográficas e históricas en que cada uno de ellos ha vivido. Sin embargo, el modo de expresión, la actitud presentativa, el tono antidramático y antididáctico y la importancia concedida a lo subjetivo, lo irracional e instintivo y al lenguaje popular, son notas que los dos comparten y que permiten trazar un paralelo entre ambos.

Es necesario también agregar que, tanto en Hamsun como en Rulfo, la carencia de una denuncia social explícita no impide la apreciación, por parte del lector, de una postura valorativa definida que implica tna profunda sabiduría acerca de las circunstancias sociales y el repudio que las mismas provocan.

El impacto innovador de ambos, por último, nos da la pauta para afirmar que en la obra de Rulfo se pueden detectar las huellas de una temprana lectura de Knut Hamsun y que la innovación de la novela europea, llevada a cabo por el autor noruego, tiene su paralelo en la innovación de la narrativa en Hispanoamérica que, varios años después, se inicia con la obra de Juan Rulfo. Tal como Hamsun, Rulfo sustituye el recuento pormenorizado de los hechos por la repercusión y consecuencias que ellos tienen sobre el ser humano, sin pretensiones de didactismo, sin voluntad de teorías explícitas, en el lenguaje sencillo del pueblo y manteniendo una «apatía» narrativa constructiva que permite al lector extraer sus propias conclusiones sin advertencias previas o juicios formulados a priori. Hamsun y Rulfo universalizan así el padecimiento de un sector y lo convierten en experiencia humana en el sentido más amplio de la palabra. 